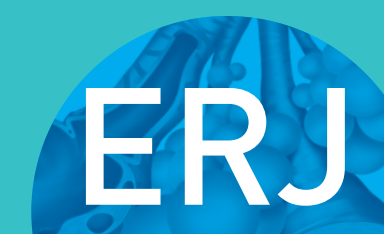

open research

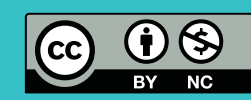

\section{Only severe COPD is associated with being underweight: results from a population survey}

\author{
Berne Eriksson [1] ${ }^{1,2}$, Helena Backman ${ }^{3}$, Apostolos Bossios ${ }^{1}$, Anders Bjerg ${ }^{1}$, \\ Linnea Hedman ${ }^{3}$, Anne Lindberg ${ }^{4}$, Eva Rönmark ${ }^{3}$ and Bo Lundbäck ${ }^{1,3}$
}

Affiliations: ${ }^{1}$ Krefting Research Centre, Institute of Medicine, Sahlgrenska Academy, University of Gothenburg, Gothenburg, Sweden. ${ }^{2}$ Dept of Internal Medicine, The Central County Hospital of Halmstad, Halmstad, Sweden. ${ }^{3}$ Dept of Public Health and Clinical Medicine, Division of Occupational and Environmental Medicine/ the OLIN Unit, University of Umeå, Umeå, Sweden. "Division of Medicine/Respiratory Medicine and Allergy, University of Umeå, Umeå, Sweden.

Correspondence: Berne Eriksson, Dept of Internal Medicine, The Central County Hospital of Halmstad, Halmstad 301 85, Sweden. E-mail: berne.erikssondatelia.com

ABSTRACT Low body mass index (BMI) and malnutrition in chronic obstructive pulmonary disease (COPD) are associated with a poor prognosis. The prevalence of underweight, as well as overweight, in severity grades of COPD is sparsely investigated in studies of the general population and the associated patterns of risk factors are not well established. The aim of the present study was to determine the association between severity grades of airflow limitation in COPD, and both underweight and obesity when corrected for possible confounding factors.

The study is based on pooled data from the OLIN (Obstructive Lung Disease in Northern Sweden) studies. Complete records with lung function, BMI and structured interview data were available from 3942 subjects (50.7\% women and $49.3 \%$ men). COPD and severity grading were defined using the Global Initiative for Chronic Obstructive Lung Disease criteria. In sensitivity analyses, the lower limit of normal was used.

The prevalence of underweight was $7.3 \%$ in severe COPD (grades 3 and 4 ) versus $2.0 \%$ in those with normal spirometry. The prevalence of obesity increased from $9.7 \%$ in grade 1 , to $16.3 \%$ in grade 2 and $20.0 \%$ in severe COPD, versus $17.7 \%$ in those with normal spirometry.

In adjusted analysis, of the COPD severity grades, only severe COPD was associated with underweight (OR 3.24, 95\% CI 1.0004-10.5), while the COPD severity grades tended to be inversely associated with overweight.

@ERSpublications

COPD grades 3 and 4 are associated with underweight http://ow.ly/GGRP300QYIN

Received: Aug 052015 | Accepted after revision: May 222016

Support statement: The study was supported by the Swedish Heart-Lung Foundation, the Health Authorities of the Northern Sweden University Region (ALF) and the County Council of Norrbotten. Funding information for this article has been deposited with the Open Funder Registry.

Conflict of interest: Disclosures can be found alongside this article at openres.ersjournals.com

Copyright $\odot$ ERS 2016. This article is open access and distributed under the terms of the Creative Commons Attribution Non-Commercial Licence 4.0. 


\section{Introduction}

Chronic obstructive pulmonary disease (COPD) is characterised by airflow limitation that is not fully reversible and pulmonary function testing is required for its diagnosis [1,2]. The disease progression of COPD often results in manifestations of several important systemic extrapulmonary effects and comorbidities [3, 4], such as fatigue, nutritional abnormalities, weight loss, skeletal muscle dysfunction and other consequences of mainly systemic inflammation $[5,6]$. The systemic effects contribute to exacerbations and to the high burden of COPD [7]. COPD is associated with low body mass index (BMI) [8-12].

Low BMI and weight loss in subjects with COPD are associated with a high risk of exacerbations [13] and represent an important risk factor for mortality $[10,14]$. The proportion of subjects with a low BMI and malnutrition in COPD varies widely from $4 \%$ to more than $40 \%[9,10,15,16]$. Most studies have been performed on hospitalised patients or in primary care settings, and still few studies presenting the prevalence of underweight in COPD subjects rely on randomly selected samples of the general population $[8,14,17]$. Some studies have found a high prevalence of both pre-obesity and obesity in COPD $[9,18]$ but research results within this area are conflicting $[10,19]$. Thus, further insights into the prevalence and distribution of BMI in COPD populations are needed.

Our hypothesis with this study was that COPD is associated with low BMI and that the degree of airflow limitation in COPD is related to BMI. We thus aimed to study the association between severity grades of airflow limitation in COPD and both underweight and obesity when corrected for possible confounding factors.

\section{Material and methods}

Study sample

The study area was the northernmost county of Sweden, Norrbotten, which covers $25 \%$ of the area of Sweden. The study sample consisted of subjects derived from three cohorts of the Obstructive Lung Disease in Northern Sweden (OLIN) studies, which were re-examined in 2002-2004. The ethics committee at the University Hospital of Northern Sweden in Umeå approved the study.

The three cohorts have been previously described in detail [20-23] and are further described in a flow chart (figure 1). The first cohort included both a randomly selected sample [20] and a sample with respiratory symptoms [21], the second cohort included symptomatic subjects [22], and the subjects of the third cohort were randomly selected from the study area [23]. The participation rate in the OLIN studies has generally been high, resulting in limited selection bias [24].

In this study, pulmonary function tests (PFTs), height and weight, along with records from structured interviews were used. Complete data were available for 3942 subjects (1999 (50.7\%) women and 1943 $(49.3 \%) \mathrm{men})$.

\section{Clinical examinations}

The questionnaire included questions about respiratory symptoms and diseases, medication, other diseases, smoking habits, occupation, socioeconomic status based on occupation, and area of domicile. The questionnaire has been used in several national and international studies, and a self-administered version has recently been externally validated against the GA ${ }^{2}$ LEN (Global Allergy and Asthma European Network) questionnaire [25].

A dry spirometer, the Vicatest 5 (Mijnhardt, Odijk, the Netherlands), was used in all PFTs. At least three slow vital capacity (SVC) manoeuvres were performed followed by forced vital capacity (FVC) measurements at least three times. The difference between the two best FVC and the two best forced expiratory volume during the first second of the expiration (FEV1) values, respectively, had to be $<5 \%$, or $<1 \mathrm{dL}$ in cases where the values were $<2.0 \mathrm{~L}$. A reversibility test was performed using $0.4 \mathrm{mg}$ salbutamol via a spacer in subjects with $\mathrm{FEV}_{1}<90 \%$ of reference values or a ratio of FEV 1 to the highest of $\mathrm{FVC}$ and SVC $<0.7$.

\section{Definitions}

COPD was defined using the Global Initiative for Chronic Obstructive Lung Disease (GOLD) criterion of the fixed ratio of $\mathrm{FEV}_{1} /(\mathrm{F}) \mathrm{VC}<0.70$. When calculating the ratio $\mathrm{FEV}_{1} /(\mathrm{F}) \mathrm{VC}$, the highest value of $\mathrm{FEV}_{1}$ before or after reversibility test, and the highest value of FVC or SVC before or after reversibility test was used. This has support in the GOLD documents [26] and in the recent ERS task force guidelines for epidemiological studies on COPD [27]. The recently published Global Lung Initiative (GLI) reference values were used [28]. In sensitivity analyses, the European Community for Steel and Coal [29], GLI and OLIN reference values [30] were used with COPD, defined using the lower limit of normal (LLN) (fifth percentile) criterion. Furthermore, a sensitivity analysis was performed within the random sample, which comprised 1566 subjects (figure 1). 
Cohort I

Recruited 1985-1986

Stratified sample based on year of birth: 1919-1920, 1934-1935, 1949-1950

Postal questionnaire: 6610; responders: 5697
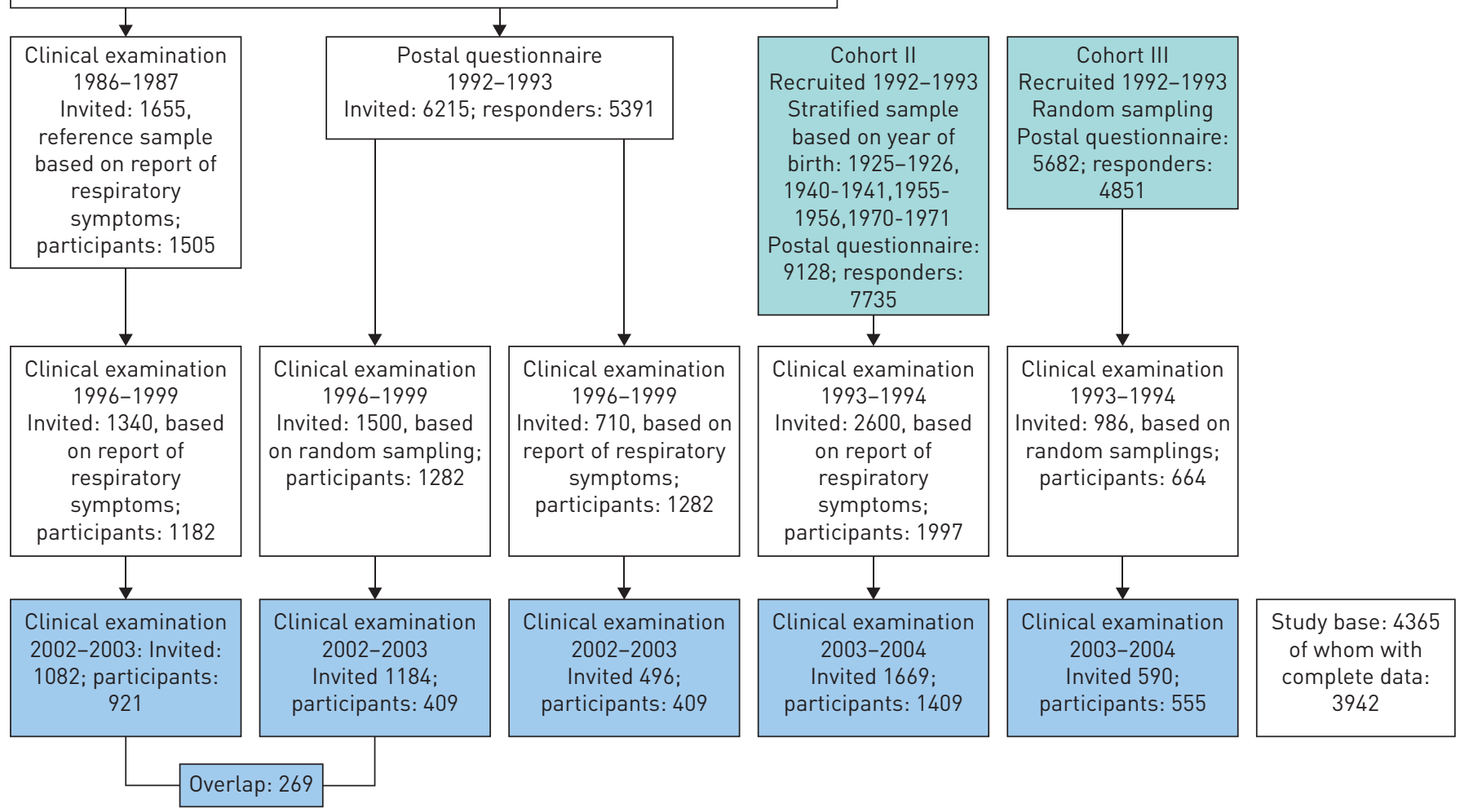

FIGURE 1 Graphic presentation of the study population drawn from three OLIN (Obstructive Lung Disease in Northern Sweden) cohorts.

Subjects with COPD were stratified into severity grades according to GOLD, which conforms closely to the European Respiratory Society/American Thoracic Society standards for COPD [2, 26]: GOLD grade 1, FEV1/(F)VC $<0.7$ and FEV1 $\geqslant 80 \%$ of reference value; GOLD grade $2, \mathrm{FEV}_{1} /(\mathrm{F}) \mathrm{VC}<0.7$ and $50 \%$ $\leqslant \mathrm{FEV}_{1}<80 \%$ of reference values; GOLD grade $3, \mathrm{FEV}_{1} /(\mathrm{F}) \mathrm{VC}<0.7$ and $30 \% \leqslant \mathrm{FEV}_{1}<50 \%$ of reference values; and GOLD grade 4, $\mathrm{FEV}_{1} /(\mathrm{F}) \mathrm{VC}<0.7$ and $\mathrm{FEV}_{1}<30 \%$ of reference values. A restrictive spirometric pattern was defined as subjects with $\mathrm{FEV} 1 /(\mathrm{F}) \mathrm{VC} \geqslant 0.70$ and $\mathrm{FVC}<80 \%$ of predicted. These subjects were excluded from the group defined as "normal spirometry".

BMI was calculated as weight in kilograms divided by the square of the height in metres and categorised according to the World Health Organization (WHO) definitions with one exception: since the number of subjects with BMI $<18.50$ was very low (33 subjects), an underweight threshold of BMI $<20$ was used, in line with previous studies $[8,10,31]$. Consequently, BMI was classified as follows: underweight, BMI $<20$; normal weight, $20 \leqslant \mathrm{BMI}<25$; pre-obesity: $25 \leqslant \mathrm{BMI}<30$; and obesity: $\mathrm{BMI} \geqslant 30$.

\section{Analyses}

Subjects with a restrictive spirometric pattern were excluded from the risk analyses of associations between COPD and BMI. The Chi-squared test (two-tailed) was used for unadjusted comparisons of proportions across groups and student's t-test was used for comparisons of means. One-way ANOVA was used for comparisons of mean BMI across more than two groups, with least significant difference post hoc analysis. A p-value $<0.05$ was considered statistically significant. The associations of BMI grades, underweight and obesity with COPD were examined by multinomial logistic regression analyses with normal weight as the reference. Variables with significant associations with COPD in unadjusted analyses were included in the adjusted analyses. The following variables were entered as covariates into the adjusted models: sex, age, smoking habits, COPD grades, socioeconomic status, coronary artery disease (CAD), heart failure, hypertension and diabetes. The results are presented as adjusted odds ratios with $95 \%$ confidence intervals with normal weight as the reference. Due to the low number of cases in COPD grade $4(n=12)$, grades 3 and 4 were combined in the risk analyses. All analyses were performed using SPSS version 20.0 (IBM, 
Armonk, NY, USA). The sensitivity analyses were performed similarly and the results of the sensitivity analyses are briefly presented in the results section.

\section{Results}

\section{Basic characteristics}

In the sample, the prevalence of COPD was $17.2 \%$ and of restrictive spirometric pattern was $10.7 \%$. Current smoking was reported by $20.8 \%$ and $40.5 \%$ had never been smokers (table 1). Obese subjects accounted for $18.1 \%$, while $2.6 \%$ were underweight. Pre-obesity was more common than normal weight ( $43.7 \%$ versus $35.6 \%, \mathrm{p}<0.001$ ).

\section{Body mass index}

Mean BMI was 26.7 (15.0-55.8). Men had a slightly higher BMI than women (26.8 versus $26.5, \mathrm{p}=0.019)$. The subjects with COPD had a lower mean BMI than subjects with a normal spirometry (25.8 versus 26.7, $\mathrm{p}<0.001)$ (figure 2), while those with a restrictive spirometric pattern had a higher BMI $(28.0, \mathrm{p}<0.001)$. Significantly higher BMI was found among ex-smokers compared to current smokers. Higher BMI was found among subjects with CAD (i.e. report of angina pectoris, myocardial infarction, percutaneous coronary intervention or coronary artery bypass grafting), hypertension, diabetes, asthma and respiratory symptoms except chronic productive cough (table 2).

We found a negative correlation between BMI and FEV1 in percentage of reference values for the group with normal spirometry $(\kappa=-3.45, \mathrm{p}<0.001)$, while for GOLD grades 1 and 2 , no significant correlations were observed. For GOLD grades 3 and 4, a lower BMI correlated to a decrease in FEV1 as a percentage of predicted values (figure 3). With decreasing BMI, the ratio of FEV1/(F)VC decreased significantly (figure 4).

\section{TABLE 1 Basic characteristics of the study population}

\begin{tabular}{|c|c|}
\hline Subjects & 3942 \\
\hline Normal spirometry & $2843(72.1 \%)$ \\
\hline COPD grade 1 & $319(8.1 \%)$ \\
\hline COPD grade 2 & $305(7.7 \%)$ \\
\hline COPD grade 3 & $43(1.1 \%)$ \\
\hline COPD grade 4 & $12(0.3 \%)$ \\
\hline All COPD & $679(17.2 \%)$ \\
\hline Restrictive spirometric pattern & $420(10.7 \%)$ \\
\hline Never-smokers & $1595(40.5 \%)$ \\
\hline Former smokers & $1481(37.6 \%)$ \\
\hline Smokers & $819(20.8 \%)$ \\
\hline Underweight ${ }^{\#}$ & $102(2.6 \%)$ \\
\hline Normal weight" & $1402(35.6 \%)$ \\
\hline Pre-obesity $^{+}$ & $1721(43.7 \%)$ \\
\hline Obesity ${ }^{\S}$ & $719(18.2 \%)$ \\
\hline Coronary artery disease & $521(13.2 \%)$ \\
\hline Heart failure & $51(1.3 \%)$ \\
\hline Arrhythmia & $238(6.0 \%)$ \\
\hline Hypertension & $1369(34.7 \%)$ \\
\hline Claudication & $151(3.8 \%)$ \\
\hline Diabetes & $357(9.1 \%)$ \\
\hline Wheeze most days a week & $424(10.8 \%)$ \\
\hline mMRC dyspnoea score $\geqslant 2$ & $668(16.9 \%)$ \\
\hline Chronic productive cough & $1072(27.2 \%)$ \\
\hline Any inhaled steroids & 897 (22.8\%) \\
\hline Any oral steroids & $301(7.6 \%)$ \\
\hline Professionals or executives & $1003(25.4 \%)$ \\
\hline Assistant nonmanual employees & $645(16.4 \%)$ \\
\hline Manual workers in industry & $768(19.5 \%)$ \\
\hline Manual workers in services & $1144(29.0 \%)$ \\
\hline Self-employed nonprofessionals & $236(6.0 \%)$ \\
\hline Other occupations & $146(3.7 \%)$ \\
\hline
\end{tabular}

COPD: chronic obstructive pulmonary disease; mMRC: modified Medical Research Council. * : body mass index (BMI) $<20$; ${ }^{\text {ๆ }}: 20 \leqslant \mathrm{BMI}<25{ }^{+}: 25 \leqslant \mathrm{BMI}<30 ;{ }^{\S}: \mathrm{BMI} \geqslant 30$. 


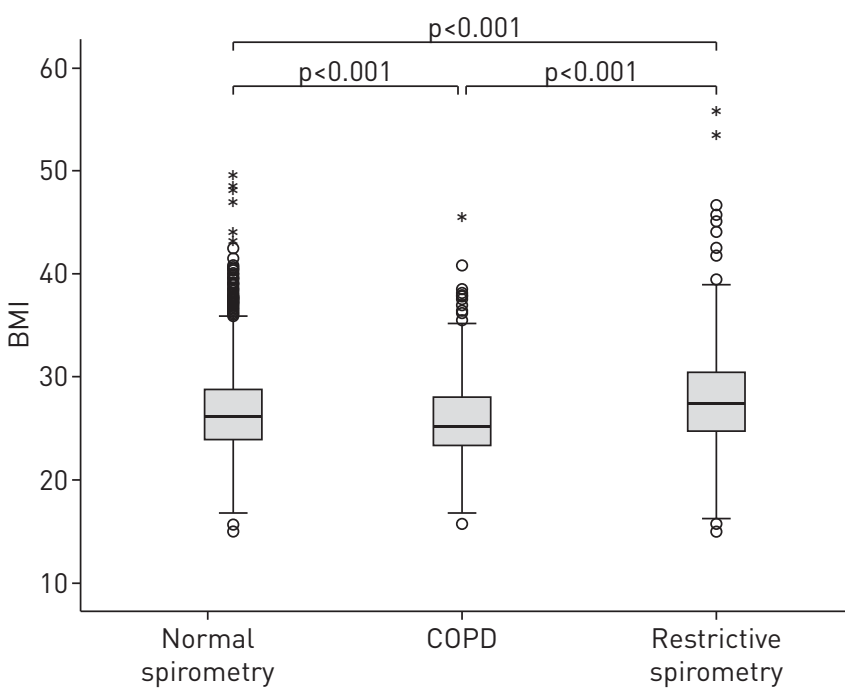

FIGURE 2 Body mass index (BMI) among subjects with normal spirometry, chronic obstructive pulmonary disease (COPD) and restrictive spirometry. Horizontal lines represent medians, boxes represent interquartile range and error bars represent 5-95th percentiles. The circles represent outliers lying outside 1.5 times the interquartile range and the asterisks represent extreme outliers $>3$ times the interquartile range.

Factors related to underweight

Among subjects who were underweight, $74 \%$ were women and $67 \%$ were former or current smokers (table 3). The proportion of subjects with underweight was larger in COPD than in subjects with a normal

\section{TABLE 2 Mean body mass index (BMI) in various subgroups}

\begin{tabular}{|c|c|c|}
\hline & Mean BMI & p-value \\
\hline All & 26.67 & \\
\hline Men & 26.83 & 0.019 \\
\hline Women & 26.52 & \\
\hline Never-smokers & 26.78 & $0.647^{+}$ \\
\hline Former smokers & 26.85 & \\
\hline Current smokers & 26.11 & $<0.001^{\S}$ \\
\hline Chronic productive cough ${ }^{\#}$ & 26.69 & NS \\
\hline Wheeze most days a week ${ }^{\#}$ & 27.97 & $<0.001$ \\
\hline mMRC dyspnoea score $2-4^{\#}$ & 28.21 & $<0.001$ \\
\hline Urban living & 26.43 & $<0.001^{f}$ \\
\hline Rural living & 27.49 & \\
\hline Asthma" & 27.29 & $<0.001$ \\
\hline COPD" & 25.83 & $<0.001$ \\
\hline Coronary artery disease ${ }^{\#}$ & 27.21 & 0.002 \\
\hline Heart failure ${ }^{\#}$ & 27.95 & 0.029 \\
\hline Arrhythmia" & 26.72 & NS \\
\hline Hypertension" & 27.83 & $<0.001$ \\
\hline Claudication" & 27.00 & NS \\
\hline Diabetes $^{\#}$ & 28.74 & $<0.001$ \\
\hline Any inhalation steroids ${ }^{\#}$ & 27.29 & $<0.001$ \\
\hline Any oral steroids" & 26.90 & NS \\
\hline Professionals and executives & 26.15 & $<0.001^{f}$ \\
\hline Assistant nonmanual employees & 26.63 & \\
\hline Manual workers in industry & 26.83 & \\
\hline Manual workers in service & 27.02 & \\
\hline Self-employed nonprofessionals & 26.68 & \\
\hline Other & 26.91 & \\
\hline
\end{tabular}




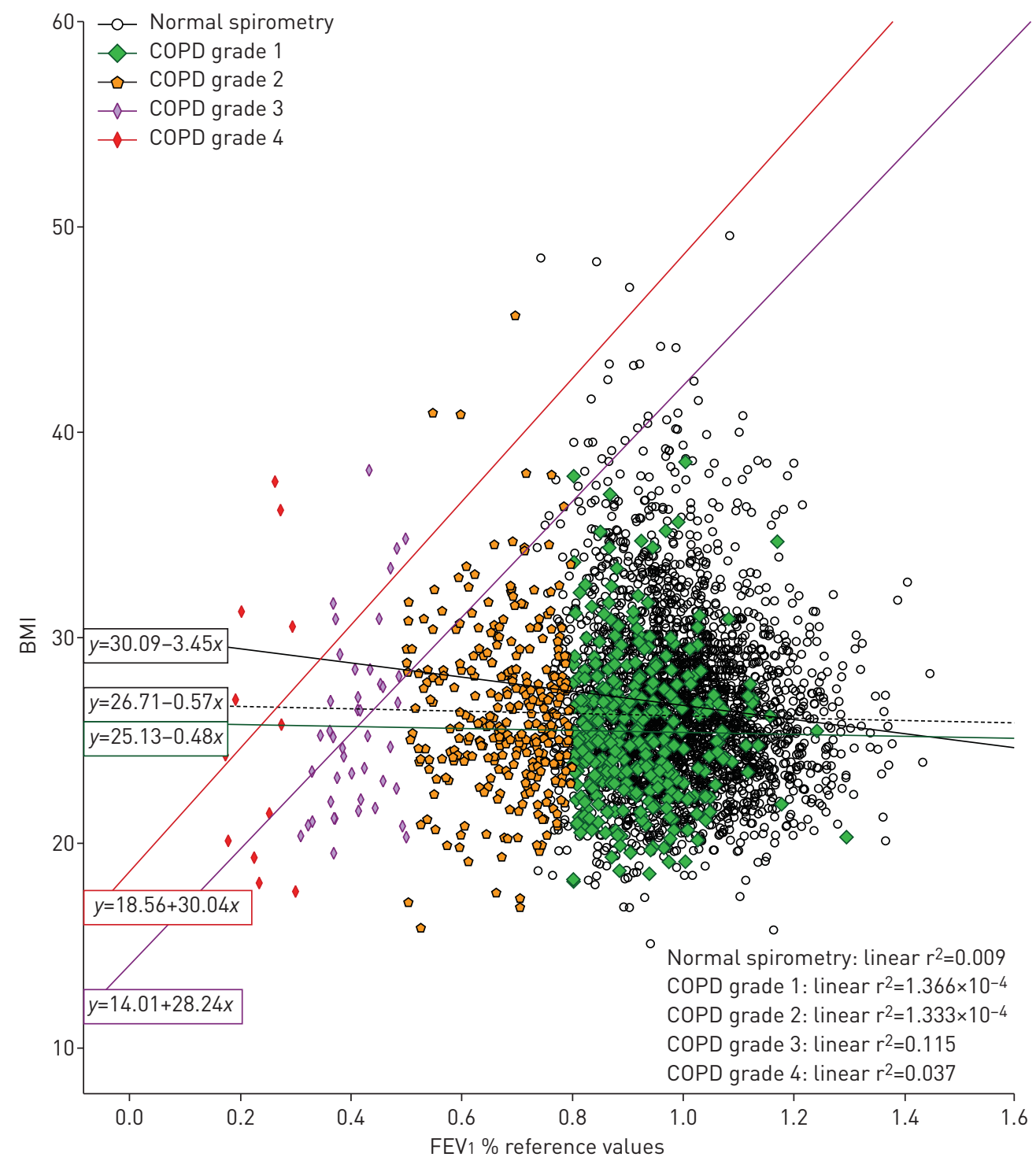

FIGURE 3 Scatter plot of body mass index (BMI) versus forced expiratory volume in the first second (FEV 1 ), and linear correlation lines for normal spirometry and chronic obstructive pulmonary disease (COPD) with COPD grades.

spirometry $(4.1 \%$ versus $1.8 \%, \mathrm{p}=0.001)$ and the proportion was highest in severe COPD (COPD grades 3-4) (7.3\%) (figure 5).

Severe COPD (COPD grades 3-4) yielded an odds ratio of 3.24 (95\% CI 1.0004-10.5) for underweight, while the other COPD severity grades were not associated with underweight. Other risk factors for underweight were female sex (OR 3.02, 95\% CI 1.65-5.53) and current smoking (OR 1.86, 95\% CI 1.07-3.26). Neither age nor comorbid diseases was significantly associated with underweight (table 4).

\section{Factors related to obesity}

Diabetes, hypertension, heart failure and CAD were all significantly more common in obese subjects than in subjects of normal weight (table 3 ). COPD was significantly less common among obese $(\mathrm{p}=0.001)$ and pre-obese $(\mathrm{p}=0.009)$ subjects than in subjects with normal weight. However, among the subjects with COPD, the prevalence of obesity tended to increase by severity of COPD from $9.7 \%$ in grade $1,16.3 \%$ in grade 2 to $20.0 \%$ in grades 3 and 4 (figure 5).

Diabetes and hypertension were also significantly and independently associated with obesity in the multivariate analysis, as were most socioeconomic groups, with professionals and executives as the reference. Increasing age (OR 0.99, 95\% CI 0.98-1.00; $\mathrm{p}=0.0050)$ and COPD grade 1 (OR 0.43, 95\% CI 


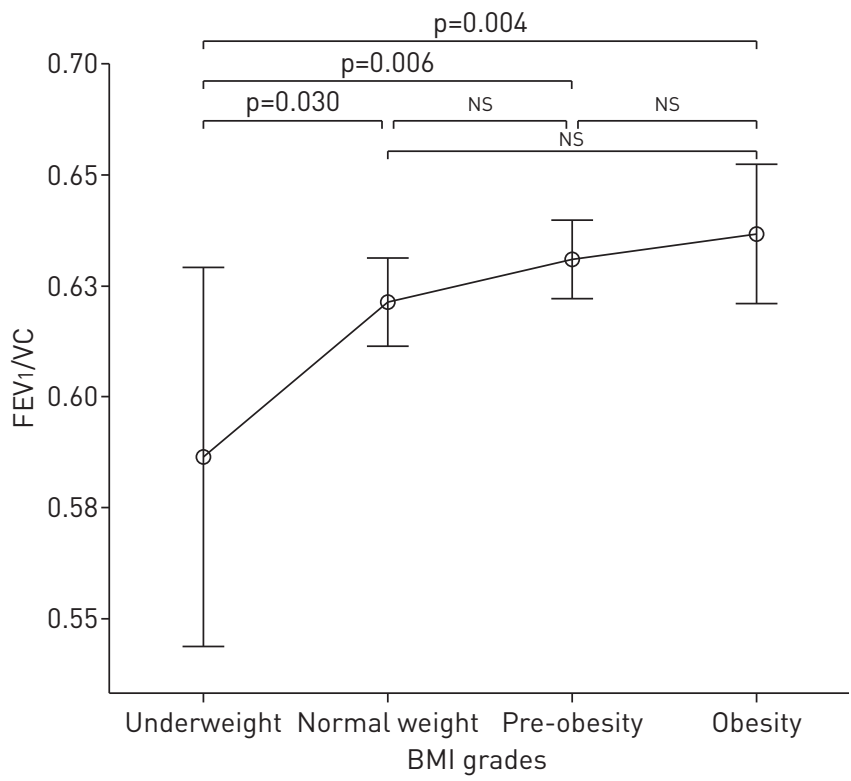

FIGURE 4 Mean forced expiratory volume in the first second (FEV 1 )/vital capacity (VC) ratio versus four body mass index (BMI) grades. Circles represent means and error bars represent $95 \%$ confidence intervals. NS: nonsignificant.

0.27-0.68) were inversely associated with obesity in the multivariate analysis, while the other COPD severity grades were not (table 4 ).

\section{Sensitivity analyses}

The LLN criterion and COPD severity grades based on the GLI and the OLIN reference values were applied in a sensitivity analysis. Furthermore, analyses were performed on the random sample using the fixed ratio definition of COPD and the GLI reference values. The results were similarly independent of criteria for COPD and reference equations. The pattern of associations of underweight yielded odds ratios

TABLE 3 Characteristics and prevalence of conditions and determinants among normal-weight, underweight, pre-obese and obese subjects

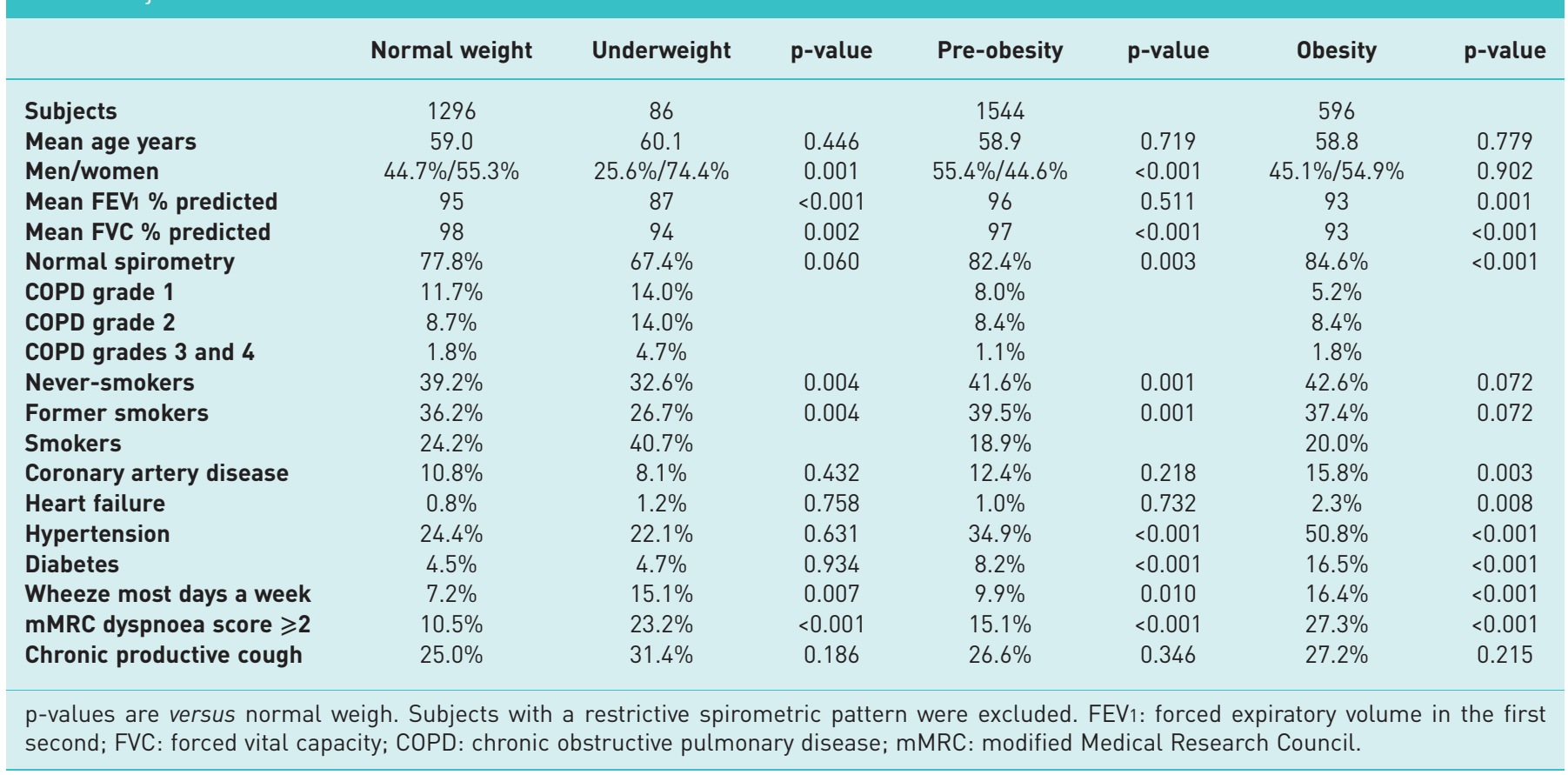




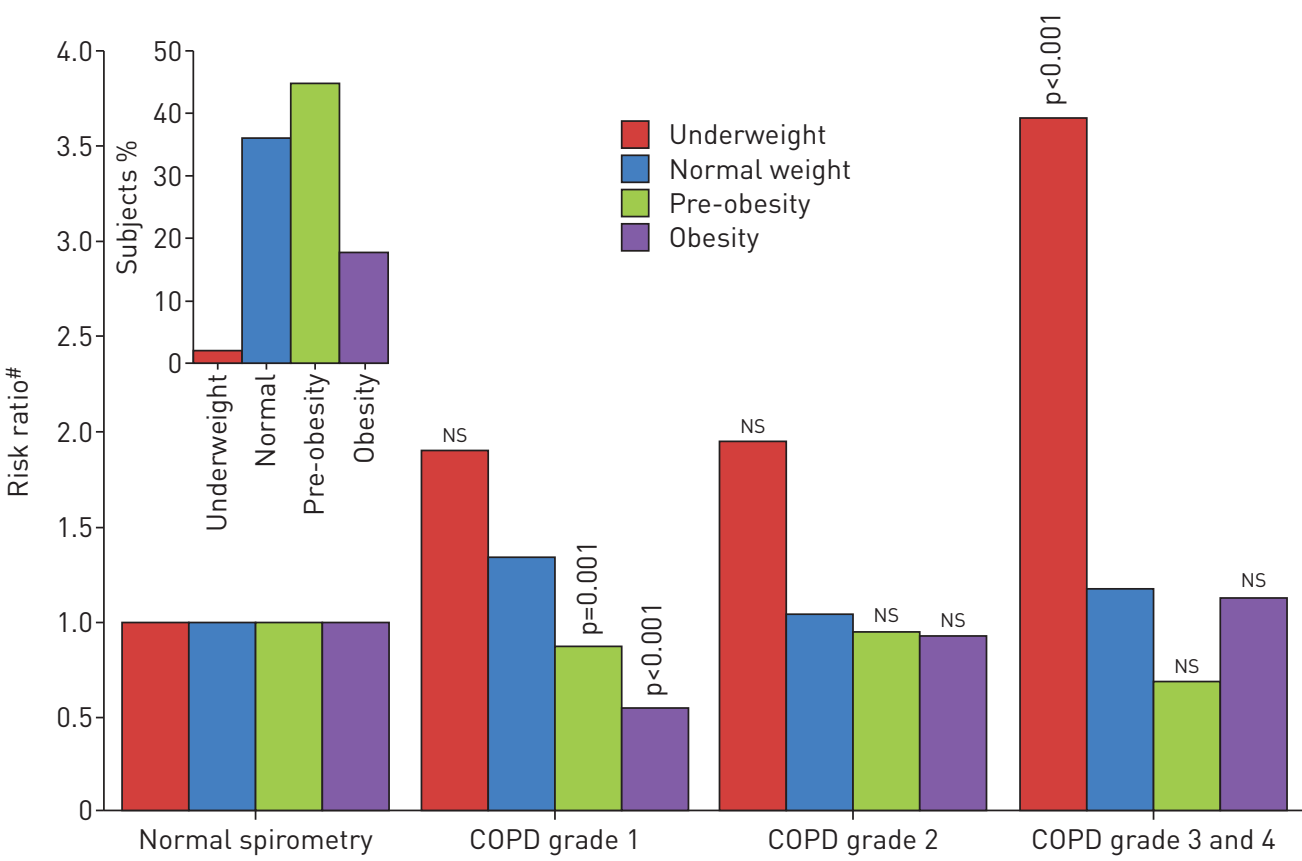

FIGURE 5 Risk ratio of body mass index (BMI) categories versus normal spirometry. $p$-values are versus normal spirometry and normal weight. Inset: distribution of BMI grades among subjects with normal spirometry. COPD: chronic obstructive pulmonary disease; NS: nonsignificant.

varying from 2.85 to 3.66 for the combined COPD severity grades 3-4 and a tendency toward inverse associations with obesity (table 5). It should be noted that using the GLI reference values and the LLN fifth percentile gives a prevalence of COPD in our study sample of only $7.0 \%$ (269 subjects), which probably yields a lack of power resulting in wide confidence intervals. Similarly, the random sample consisted of 1566 subjects and, although the prevalence of COPD was similar to the whole study sample (16.3\%), the confidence intervals became too wide to reach the significance of the association of COPD severity grades 3-4 with underweight.

TABLE 4 Adjusted analyses of determinants of underweight and obesity versus normal weight

\begin{tabular}{|c|c|c|c|}
\hline & Subjects & Underweight & Obesity \\
\hline Female & 1017 & $3.02(1.65-5.53)$ & $0.92(0.72-1.17)$ \\
\hline Age & & $1.01(0.99-1.03)$ & $0.99\left(0.98-1.00^{9}\right)$ \\
\hline Never-smoker & 727 & 1.0 & 1.0 \\
\hline Ex-smoker & 663 & $0.96(0.54-1.72)$ & $0.90(0.69-1.16)$ \\
\hline Smoker & 445 & $1.86(1.07-3.26)$ & $0.84(0.62-1.15)$ \\
\hline Normal spirometry & 1462 & 1.0 & 1.0 \\
\hline COPD grade 1 & 189 & $1.27(0.64-2.53)$ & $0.43(0.27-0.68)$ \\
\hline COPD grade 2 & 169 & $1.43(0.70-2.94)$ & $0.83(0.55-1.26)$ \\
\hline COPD grade $3-4$ & 35 & $3.24\left(1.00^{\#}-10.5\right)$ & $0.62(0.26-1.48)$ \\
\hline Professional or executive & 496 & 1.0 & 1.0 \\
\hline Assistant nonmanual employee & 304 & $1.39(0.70-2.74)$ & $1.38(0.96-2.00)$ \\
\hline Manual worker in industry & 344 & $1.90(0.86-4.18)$ & $1.59(1.11-2.28)$ \\
\hline Manual worker in service & 531 & $1.02(0.55-1.90)$ & $1.83(1.33-2.51)$ \\
\hline Self-employed nonprofessional & 112 & $1.60(0.56-4.55)$ & $1.53(0.92-2.56)$ \\
\hline Other & 50 & $1.55(0.48-5.00)$ & $1.49(0.71-3.13)$ \\
\hline Coronary artery disease & 229 & $0.81(0.35-1.90)$ & $1.18(0.83-1.67)$ \\
\hline Heart failure & 24 & $1.40(0.16-12.0)$ & $1.95(0.79-4.82)$ \\
\hline Hypertension & 571 & $0.80(0.46-1.39)$ & $2.97(2.34-3.78)$ \\
\hline Diabetes & 138 & $1.14(0.40-3.34)$ & $3.10(2.10-5.58)$ \\
\hline
\end{tabular}

Data are presented as odds ratios $(95 \% \mathrm{CI}$ ) unless otherwise stated. COPD: chronic obstructive pulmonary disease. ${ }^{\#}: 1.0004, p=0.0499 ;$ ๆ: 0.9983, $p=0.0050$. 
TABLE 5 Sensitivity analysis of the association between chronic obstructive pulmonary disease (COPD) severity grades and underweight and obesity using different reference values in a multinomial regression analysis with normal weight as the reference

\begin{tabular}{|c|c|c|c|}
\hline & Subjects & Underweight & Obesity \\
\hline \multicolumn{4}{|c|}{ OLIN reference values using LLN for COPD and restrictive spirometry } \\
\hline Non-COPD & 1462 & 1 & 1 \\
\hline COPD grade 2 & 114 & $1.69(0.78-3.66)$ & $0.53(0.30-0.94)$ \\
\hline COPD grades 3 and 4 & 35 & $3.38(1.16-9.82)$ & $0.52(0.20-1.36)$ \\
\hline \multicolumn{4}{|c|}{ Berglund reference values, fixed ratio } \\
\hline COPD grade 2 & 183 & $1.49(0.71-3.14)$ & $0.92(0.60-1.40)$ \\
\hline COPD grades 3 and 4 & 52 & $3.66(1.24-10.84)$ & $0.52(0.22-1.25)$ \\
\hline \multicolumn{4}{|c|}{ ECSC reference values, fixed ratio } \\
\hline Non-COPD & 1590 & 1 & 1 \\
\hline COPD grade 1 & 199 & $1.14(0.58-2.25)$ & $0.40(0.26-0.63)$ \\
\hline COPD grade 2 & 157 & $1.46(0.70-3.0)$ & $0.86(0.56-1.30)$ \\
\hline COPD grade 2 & 142 & $1.30(0.55-3.06)$ & $0.87(0.61-1.26)$ \\
\hline COPD grades 3 and 4 & 42 & $2.85(0.90-9.03)$ & $0.54(0.28-1.05)$ \\
\hline \multicolumn{4}{|c|}{ Analyses on random sample with fixed ratio and GLI reference values } \\
\hline Non-COPD & 573 & 1 & 1 \\
\hline COPD grade 1 & 75 & $1.77(0.65-4.87)$ & $0.46(0.22-0.98)$ \\
\hline COPD grade 2 & 53 & $1.42(0.41-4.95)$ & 0.70 (0.31-1.58) \\
\hline COPD grades 3 and 4 & 9 & $2.91(0.31-27.76)$ & $0.80(0.13-4.80)$ \\
\hline \multicolumn{4}{|c|}{$\begin{array}{l}\text { Data are presented as odds ratios }(95 \% \mathrm{CI}) \text { unless otherwise stated. All analyses were adjusted for sex, age, smoking habits, socioeconomic } \\
\text { status, coronary artery disease, heart failure, hypertension and diabetes with the same model as in table } 4 \text {. OLIN: Obstructive Lung Disease in } \\
\text { Northern Sweden: LLN: lower limit of normal; ECSC: European Community for Steel and Coal; GLI: Global Lung Initiative. }\end{array}$} \\
\hline
\end{tabular}

\section{Discussion}

In our population-based study, we found a significant association between low BMI and COPD. The difference in mean BMI between subjects not having COPD and subjects in the different severity grades of COPD was small. Furthermore, only severe COPD was significantly associated with underweight. The association of underweight and severe COPD remained after adjusting for smoking habits and other possible confounders, and it was insensitive to both the definition of COPD and the choice of reference values. We could not establish a correlation between obesity and COPD; on the contrary, the results indicated an inverse association for all COPD severity grades. Our finding of the association between low BMI and COPD is consistent with some other studies, but not all. The few studies of the general population that have addressed this issue have mainly compared BMI in COPD versus non-COPD $[8,15]$.

Several studies have defined underweight differently, with BMI cut-offs varying from 18.5 to $21.0[9,10,15]$. In a study from Canada, the prevalence of subjects with the WHO-defined underweight category (BMI $<18.5$ ) was $3.9 \%$ among subjects with COPD versus $1.9 \%$ in subjects without COPD [15], in line with our results. In the first US National Health and Nutrition Examination Survey, the prevalence of WHO-defined underweight was considerably higher and $\sim 10 \%$ in each severity grade of COPD [14]. In contrast, a clear association between COPD and underweight defined as BMI $<21$ was found in a primary care setting in the Netherlands, with a prevalence of underweight in COPD severity grade 4 of $47 \%$, and in grades 3,2 and 1 of $17 \%, 10 \%$ and $7 \%$, respectively [9]. Underweight, particularly when defined as a BMI $<18.5$ as a marker for cachexia and malnutrition, is associated with increased mortality [32].

The results of several studies with respect to the association of obesity in COPD are conflicting. Some studies have found a high prevalence of obesity in COPD [18] or an association of COPD and metabolic syndrome [33], while other studies have not found a higher prevalence of obesity in COPD [8, 11].

In our study, the prevalence of obesity among all those with COPD was lower than among those with a normal spirometry. Neither the obesity nor the pre-obesity distribution showed obvious associations with COPD or the COPD severity grades, and in the adjusted analyses, there tended to be an inverse 
association; however, significantly so for COPD severity grade 1, and one of the sensitivity analyses for COPD severity grade 2 (i.e. moderate COPD).

However, the prevalence of obese subjects tended to increase from mild COPD to severe COPD, and obesity was even more common than underweight in severe COPD. These results are consistent with some other population-based studies $[8,11]$. The prevalence of obesity in the referred Dutch primary care COPD cohort [9] was $18 \%$ and somewhat higher than the $13 \%$ in our study.

The findings of a tendency toward increasing BMI with increasing obstruction are in line with a recent study from Denmark suggesting that COPD may be underestimated in obese subjects [34]. High BMI or other signs of the metabolic syndrome have been associated with lower lung function, but seem to affect both FEV1 and VC [35]. Quitting smoking often results in increased BMI. Consequently, former smokers had a higher BMI in our study, but this association was absent in the adjusted analysis for obesity.

Our study has both strengths and limitations. Making conclusions based on spirometry requires well-performed lung function testing where the cooperation of subjects is crucial. Our personnel are well trained and experienced, both in performing lung function testing and interviews. As the study sample was not entirely randomly selected, precise estimates of prevalence in the general population cannot be presented. The sample was somewhat enriched with symptomatic subjects in order to increase the statistical power. Despite that, the confidence intervals were wide. Nevertheless, the sensitivity analyses verified the observed association between underweight and COPD severity grades 3-4 both in the random sample and when using different definitions of COPD and different reference equations for lung function. As the study was a follow-up survey, subjects with severe COPD may have died before the 2002-2004 follow-up, thus resulting in fewer cases of COPD severe grades 3-4, with negative effects on the statistical power for detecting significant associations. This has probably not had any major effect on the magnitude of the observed associations of underweight and COPD severity grades 3-4.

Mean BMI and the prevalence of obesity increased in Sweden up to 2002, but from 2004 to 2014, the mean BMI for subjects aged 35 years and over increased from 25.42 to 25.86 [36,37]. The prevalence of underweight did not change during this period, being steady at $2 \%$, while the prevalence of obesity increased from $11 \%$ to $14 \%$. Since our study was limited to the associations of COPD with BMI and BMI grades, this change in the prevalence of BMI grades should not affect the pattern of association.

Data on other diseases than COPD were based on self-reports at structured interviews. Regarding the medical history of heart diseases and hypertension, there is a good agreement between self-report of disease and objectively assessed hypertension, angina pectoris, myocardial infarction and stroke [38], but not of heart failure [39]. However, since these associations were not the primary aim of our analyses, this does not affect our conclusions.

Anthropometric measures were collected at the examination, and data about lung function and BMI are valid. There are some objections to BMI as a marker for disease. The boundaries for classification are arbitrary and different cut-offs are used [40]. BMI is not an ideal measure for evaluating body composition with respect to the amount of adipose tissue or muscles, i.e. of fat-free mass.

In conclusion, mean BMI was slightly but significantly lower in subjects with COPD. However, only severe COPD was associated with underweight, while mild and moderate COPD were not. This finding was consistent irrespective of both the definition of COPD and choice of reference values for lung function. No significant positive association between COPD grades and obesity was found.

\section{Acknowledgements}

The authors thank the clinical staff in Luleå and Boden for help with collecting the data.

\section{References}

1 Vestbo J, Hurd SS, Agustí AG, et al. Global strategy for the diagnosis, management, and prevention of chronic obstructive pulmonary disease. Am J Respir Crit Care Med 2013; 87: 347-365.

2 Celli BR, MacNee W. Standard for the diagnosis and treatment of patients with COPD: a summary of the ATS/ ERS position paper. Eur Respir J 2004; 23: 932-946.

3 Agusti A, Noguera A, Sauleda J, et al. Systemic effects of chronic obstructive pulmonary disease. Eur Respir J 2003. 21: $347-360$.

4 Gan W, Man S, Senthilselvan A, et al. Association between chronic obstructive pulmonary disease and systemic inflammation: a systematic review and a meta-analysis. Thorax 2004; 59: 574-580.

5 Barnes PJ, Celli BR. Systemic manifestations and comorbidities of COPD. Eur Respir J 2009; 33: 1165-1185.

Fabbri LM, Rabe KF. From COPD to chronic systemic inflammatory syndrome? Lancet 2007; 370: 797-799.

Drost EM, Skwarski KM, Sauleda J, et al. Oxidative stress and airway inflammation in severe exacerbations of COPD. Thorax 2005; 60: 293-300.

8 de Oca M, Tálamo C, Perez-Padilla R, et al. Chronic obstructive pulmonary disease and body mass index in five Latin America cities: the PLATINO study. Respir Med 2008; 102: 642-650. 
9 Steuten LMG, Creutzberg EC, Vrijhoef HJ, et al. COPD as a multicomponent disease: inventory of dyspnoea Underweight, obesity and fat free mass depletion in primary care. Prim Care Respir J 2006; 15: 84-91.

10 Hallin R, Gudmundsson G, Ulrik CS, et al. Nutritional status and long-term mortality in hospitalised patients with chronic obstructive pulmonary disease (COPD). Respir Med 2007; 101: 1954-1960.

11 Mannino DM, Ford, Redd SC. Obstructive and restrictive lung disease and functional limitation: data from the Third National Health and Nutrition Examination. J Intern Med 2003; 254: 540-547.

12 Franssen FM, O’Donnell DE, Goossens GH, et al. Obesity and the lung: 5. Obesity and COPD. Thorax 2008; 63: $1110-1117$.

13 Hallin R, Koivisto-Hursti UK, Lindberg E, et al. Nutritional status, dietary energy intake and the risk of exacerbations in patients with chronic obstructive pulmonary disease (COPD). Respir Med 2006; 100: 561-567.

14 Landbo $\mathrm{C}$, Prescott E, Lange $\mathrm{P}$, et al. Prognostic value of nutritional status in chronic obstructive pulmonary disease. Am J Respir Crit Care Med 1999; 160: 1856-1861.

15 Curkendall SM, DeLuise C, Jones JK, et al. Cardiovascular disease in patients with chronic obstructive pulmonary disease, Saskatchewan Canada cardiovascular disease in COPD patients. Ann Epidemiol 2006; 16: 63-70.

16 Pothirat C, Phetsuk N, Deesomchok A, et al. Clinical characteristics, management in real world practice and long-term survival among COPD patients of Northern Thailand COPD club members. J Med Assoc Thai 2007; 90: 653-662.

17 Mannino DM, Thorn D, Swensen A, et al. Prevalence and outcomes of diabetes, hypertension and cardiovascular disease in COPD. Eur Respir J 2008; 32: 962-969.

18 Eisner MD, Blanc PD, Sidney S, et al. Body composition and functional limitation in COPD. Respir Res 2007; 8: 7.

19 Mannino DM, Buist AS, Petty TL, et al. Lung function and mortality in the United States: data from the First National Health and Nutrition Examination Survey follow up study. Thorax 2003; 58: 388-393.

20 Lundbäck B, Lindberg A, Lindström $\mathrm{M}$, et al. Not 15 but 50\% of smokers develop COPD? Report from the Obstructive Lung Disease in Northern Sweden Studies. Respir Med 2003; 97: 115-122.

21 Lindberg A, Jonsson AC, Rönmark E, et al. Ten-year cumulative incidence of COPD and risk factors for incident disease in a symptomatic cohort. Chest 2005; 127: 1544-1552.

22 Lindström M, Jönsson E, Larsson $\mathrm{K}$, et al. Underdiagnosis of chronic obstructive pulmonary disease in Northern Sweden. Int J Tuberc Lung Dis 2001; 6: 76-84.

23 Lindberg A, Jonsson A-C, Rönmark E, et al. Prevalence of chronic obstructive pulmonary disease according to BTS, ERS, GOLD and ATS criteria in relation to doctor's diagnosis, symptoms, age, gender, and smoking habits. Respiration 2005; 72: 471-479.

24 Rönmark E, Lundqvist A, Lundbäck B, et al. Non-responders to a postal questionnaire on respiratory symptoms and diseases. Eur I Epidemiol 1999; 15: 293-299.

25 Ekerljung L, Rönmark E, Lötvall J, et al. Questionnaire layout and wording influence prevalence and risk estimates of respiratory symptoms in a population cohort. Clin Respir J 2013; 7: 53-63.

26 Global Initiative for Chronic Obstructive Lung Disease. Global Strategy for the Diagnosis, Management, and Prevention of Chronic Obstructive Pulmonary Disease 2015. Available from: www.goldcopd.org

27 Bakke PS, Rönmark E, Eagan T, et al. ERS task force. Recommendations for epidemiological studies on COPD. Eur Respir J 2011; 38: 1261-1277.

28 Quanjer PH, Stanojevic S, Cole TJ, et al. Multi-ethnic reference values for spirometry for the 3-95 year age range: the Global Lung Function 2012 equations. Eur Respir J 2012; 40: 1324-1330.

29 Quanjer PH, Tammeling GJ, Cotes JE, et al. Lung volumes and forced ventilatory flows. Eur Respir J 1993; 6: Suppl. 16, 5S-40S.

30 Backman H, Lindberg A, Sovijärvi A, et al. Evaluation of the GLI-2012 reference values for spirometry in a Swedish population sample. BMC Pulm Med 2015; 15: 26.

31 Eriksson B, Lindberg A, Müllerova $\mathrm{H}$, et al. Association of heart diseases with COPD and restrictive lung function - results from a population survey. Respir Med 2013; 107: 98-106.

32 Flegal KM, Graubard BI, Williamson DF, et al. Excess deaths associated with underweight, overweight, and obesity. JAMA 2005; 293: 1861-1867.

33 Lam KBH, Jordan RE, Jiang CO, et al. Airflow obstruction and metabolic syndrome: the Guangzhou Biobank Cohort Study. Eur Respir J 2010; 35: 317-323.

34 Colak Y, Marott JL, Vestbo J, et al. Overweight and obesity may lead to under-diagnosis of airflow limitation: findings from the Copenhagen City Heart Study. COPD 2015; 12: 5-13.

35 Rubinstein I, Zamel N, DuBarry L, et al. Airflow limitation in morbidly obese nonsmoking men. Ann Intern Med 1990; 112: 828-832.

36 Statistics Sweden. www.scb.se Date last accessed: February 8, 2016.

37 Public Health Agency of Sweden. Folkhälsan i Sverige, Årsrapport 2014 [Public Health in Sweden, Annual Report 2014]. https://www.folkhalsomyndigheten.se/publicerat-material/publikationer/Folkhalsan-i-Sverige-Arsrapport-2014/ Date last accessed: February 8, 2016.

38 Lampe F, Walker M, Lennon L, et al. Validity of a self-reported history of doctor-diagnosed angina. J Clin Epidemiol 1999; 52: 73-81.

39 Olofsson M, Edebro D, Boman K. Are elderly patients with suspected HF misdiagnosed? A primary health care center study. Cardiology 2007; 107: 226-232.

40 James WPT, Francois P. The choice of cut-off point for distinguishing normal body weight from underweight or "chronic energy deficiency" in adults. Eur J Clin Nutr 1994; 48: 179-184. 